immersion in cold water causes bradycardia. ${ }^{4}$ These effects may occur during burial in an avalanche of snow. Hypothermia often occurs in burial in an avalanche. ${ }^{12}$ The face is often the only area unprotected by clothing and in direct contact with the snow, which may be important as it is the face that triggers the diving reflex. This is unlike immersion in cold water, when cooling is more uniform. During immersion water may enter the nasopharynx, causing cooling of the brain, or may be inhaled, causing rapid cooling of the heart and brain before circulation stops. Although this would not occur during burial in snow, snow has been found packed in the mouth and nose and may be inhaled, possibly with similar effects ( $\mathrm{N}$ J MacDonald, personal observations).

I thank Dr M Harris of Northwick Park Hospital for his help in preparing this report.

1 MacInnes H. International mountain rescue handbook. 2nd ed. London: Constable, 1984.

2 Fraser C. The avalanche enigma. London: John Murray, 1966.

3 Siebke H, Breivik H, Rod T, Lind B. Survival after 40 minutes' submersion without cerebral sequelae. Lancet $1975 ;$; : $1275-7$.

4 Harries M. Drowning and near drowning. Br.Med f 1986;293:122-4.

(Accepted 5 February 1987)

Health Centre, Aviemore PH22 1SY

DUNCAN GRAY, MB, CHB, trainee general practitioner

\section{Gynaecomastia induced by phenytoin in men with epilepsy}

Long term anticonvulsant treatment may be associated with loss of libido and gonadal dysfunction. ${ }^{12}$ Changes in sex hormone binding globulin and free testosterone concentrations may explain these phenomena..$^{134} \mathrm{We}$ recently observed gynaecomastia in five men receiving long term anticonvulsant treatment, phenytoin being common treatment in all five cases.

\section{Case reports}

Case 1-A 42 year old man with chronic temporal lobe epilepsy of several years' duration who had taken phenytoin $100 \mathrm{mg}$ thrice daily for five years and carbamazepine $200 \mathrm{mg}$ thrice daily developed a tender lump in the right breast and enlargement of the left breast. There was no loss of libido, and the genitalia were clinically normal. Plasma prolactin concentration was normal. The breast lump was excised, and histological examination showed benign hyperplasia. When phenytoin was stopped his gynaecomastia resolved.

Case 2-A 20 year old man with a two year history of infrequent major seizures had been treated with phenytoin $300 \mathrm{mg}$ daily since the diagnosis of epilepsy and valproate $200 \mathrm{mg}$ daily. He developed tender enlargement of both breasts; libido was undisturbed, and the genitalia were normal. Carbamazepine was substituted for phenytoin, and the gynaecomastia resolved.

Case 3-A 36 year old man with a 16 year history of infrequent generalised convulsions had received phenytoin $300 \mathrm{mg}$ daily since the diagnosis of epilepsy with clobazam $20 \mathrm{mg}$ at night. During the past four years he had been noted to have moderate gynaecomastia. Genitalia and secondary sexual characteristics were normal, and there were no other abnormalities. His libido was normal

Case 4-A 42 year old man with a 36 year history of epilepsy associated with a right temporal focus on electroencephalography complained of impotence and breast enlargement. He had received phenytoin $300 \mathrm{mg}$ daily for over 20 years. His libido was normal. Clinical examination confirmed moderate gynaecomastia; there were no other abnormalities.

Case 5-A 32 year old man with a 10 year history of focal temporal lobe fits and generalised convulsions had moderate gynaecomastia. He described normal libido, and secondary sexual characteristics were normal. Treatment had consisted of phenytoin $300-400 \mathrm{mg}$ daily for 10 years and phenobarbitone.

Results of liver function tests were normal in all patients. The table shows hormonal data for three patients (cases 3,4, and 5). The phenytoin concentrations in all five patients were in or below the usual therapeutic range; in only one patient (case 4) were toxic values recorded occasionally. Apart from transient ataxia in this patient and minor gum hyperplasia in case 3 there were no other signs of drug toxicity.

\section{Comment}

The resolution of gynaecomastia when phenytoin was stopped in cases 1 and 2 suggested a causal relation with this drug and raised the possibility that phenytoin was responsible for the gynaecomastia in the remaining three patients, who underwent more detailed endocrine assessment.

A possible mechanism is provided by reports of a reduction in circulating free testosterone concentration in patients receiving long term treatment
Sex steroid and gonadotrophin concentrations in three patients

\begin{tabular}{|c|c|c|c|c|}
\hline & Normal range & Case 3 & Case 4 & Case 5 \\
\hline Total testosterone ${ }^{\star}(\mathrm{nmol} / \mathrm{l})$ & $10 \cdot 4-34 \cdot 7$ & $22 \cdot 0$ & $22 \cdot 0$ & $14 \cdot 0$ \\
\hline Total $17 \beta$ oestradiol ${ }^{\star}(\mathrm{pmol} / \mathrm{l})$ & $14-180$ & 159 & 168 & 200 \\
\hline Sex hormone binding globulin $\dagger(\mathrm{nmol} / \mathrm{l})$ & $10-50$ & 69 & 43 & 15 \\
\hline Luteinising hormone $\neq(\mathrm{IU} / \mathrm{I})$ & $2-10$ & $8 \cdot 1$ & $22 \cdot 1$ & $5 \cdot 0$ \\
\hline Follicle stimulating hormone $\neq(\mathrm{IU} / \mathrm{l})$ & $2-5$ & $13 \cdot 7$ & $9 \cdot 7$ & 0.9 \\
\hline Free androgen index $\$$ & median $75 \cdot 2$ & $31 \cdot 9$ & $51 \cdot 2$ & $93 \cdot 3$ \\
\hline Free oestrogen index $\|$ & median 0.37 & 0.23 & 0.39 & $1 \cdot 33$ \\
\hline Prolactin (mU/l) & $<360$ & 465 & 137 & 55 \\
\hline
\end{tabular}

^St Thomas's Hospital SAS assay.

†Method in ref 3 .

†Chelsea kit.

STestosterone $\times 100 /$ sex hormone binding globulin.

$\|$ Oestradiol $\times 0 \cdot 1 / \mathrm{sex}$ hormone binding globulin.

with various anticonvulsants. ${ }^{14}$ The free androgen index was low, gonadotrophin concentration raised, and free oestrogen index normal in cases 3 and 4 , whereas in case 5 the free androgen index was normal but the free oestrogen index raised. The data are consistent with the hypothesis that phenytoin treatment decreases free testosterone concentration as a result of increasing the concentration of sex hormone binding globulin and induces increased conversion of testosterone to $17 \beta$ oestradiol. Gynaecomastia may result from either one or a combination of these effects ${ }^{5}$ and, with loss of libido and subfertility, should be borne in mind as a possible side effect of long term treatment with phenytoin. One patient (case 3) had a slightly raised plasma prolactin concentration; two others (cases 4 and 5) had normal concentrations. Although certain anticonvulsants have been associated with increased plasma prolactin concentrations, ${ }^{2}$ this does not seem to have been relevant to the gynaecomastia observed in our patients.

We are grateful to Dr J Wright for referring two of the patients (cases 1 and 2). We also thank Dr H L J Makin and the staff of the steroid laboratory, department of chemical pathology, for the hormone assays.

1 Toone BK, Wheeler $M$, Nanjee $M$, Fenwick $P$, Grant RHE. Sex hormones, sexual drive and plasma anticonvulsant levels in male epileptics. In: Parsonage M, Grant RHE, Craig AG, Ward plasma anticonvulsant levels in male epileptics. In: Parsonage M, Grant RHE, Craig AG, Ward Press, 1983:313-7.

2 Rodin E, Subramamian MG, Gilroy J. Investigation of sex hormones in male epileptic patients. Epilepsia 1984;25:690-4.

3 Barragry JM, Makin HLJ, Trafford DJH, Scott DF. Effects of anticonvulsants on plasma testosterone and sex hormone binding globulin levels. F Neurol Neurosurg Psychiatry 1978;41: 913-4.

4 Dana-Haeri J, Oxley J, Richens A. Reduction of free testosterone by antiepileptic drugs. Br Med f 1982;284:85-6.

5 Turkington RW, Topper YJ. Androgen inhibition of mammary gland differentiation in vitro. Endocrinology 1967;80:329-36.

(Accepted 28 November 1986)

The London Hospital, London E1 1BB

J P MONSON, MD, MRCP, senior lecturer in endocrinology, medical unit

D F SCOTT, FRCP, DPM, consultant in charge, department of clinical neurophysiology

Correspondence to: Dr Scott.

\section{Severe cholestasis associated with stanozolol}

Although stanozolol has been in clinical use for over 20 years, the Committee on the Safety of Medicines knows of only four cases of jaundice associated with it and only one case has been reported. ${ }^{1}$ We report on three patients with severe cholestatic jaundice, two with associated renal failure, in whom stanozolol was the only agent that could be implicated.

\section{Case reports}

All three patients presented with jaundice and pruritus. Their history and examination did not show any evidence of liver disease, and none had previously experienced any adverse drug reactions. In all cases hepatitis A and B were excluded by specific serological tests. Autoantibodies, including antimitochondrial antibody, were also absent in cases 1 and 2. Extrahepatic obstruction was excluded by operative cholangiography in case 1, ultrasonography and endoscopic cholangiography in case 2, and ultrasonography alone in case 3 . 
One patient (case 3) had been taking frusemide and amiloride for six months for cardiac failure. The two other patients were taking no drugs other than stanozolol. The renal failure in cases 1 and 3 occurred during the period of cholestasis and in case 3 necessitated short term peritoneal dialysis. Liver biopsy in cases 1 and 3 showed severe cholestasis and in case 2 showed mixed cholangiolitic and hepatitic changes. Histological examination of the kidney in case 3 showed acute tubular necrosis. The table gives clinical details and biochemical findings. All three patients recovered biochemically over three to six months after withdrawal of the drug.

Faundice associated with stanozolol

\begin{tabular}{|c|c|c|c|}
\hline & Case 1 & Case 2 & Case 3 \\
\hline $\begin{array}{l}\text { Age (years) } \\
\text { Sex } \\
\text { Indication for treatment }\end{array}$ & $\begin{array}{c}\mathbf{6 5} \\
\mathbf{F} \\
\text { Varicose } \\
\text { ulcer }\end{array}$ & $\begin{array}{l}\stackrel{62}{F} \\
\text { Varicose } \\
\text { eczema }\end{array}$ & $\begin{array}{l}65 \\
M \\
\text { Varicose } \\
\text { ulcer }\end{array}$ \\
\hline $\begin{array}{l}\text { Duration of treatment before symptoms } \\
\text { (months) } \\
\text { Daily dose of stanozolol (mg) } \\
\text { Other treatment }\end{array}$ & $\begin{array}{c}4 \\
10 \\
\text { None }\end{array}$ & $\begin{array}{c}5 \\
10 \\
\text { None }\end{array}$ & $\begin{array}{c}1 \\
10 \\
\text { Frusemide, } \\
\text { amiloride (for } \\
6 \text { months) }\end{array}$ \\
\hline
\end{tabular}

Biochemical findings *

\begin{tabular}{|c|c|c|c|}
\hline Maximum bilirubin $(\mu \mathrm{mol} / \mathrm{l})(<17 \mu \mathrm{mol} / \mathrm{l})$ & 660 & 732 & 798 \\
\hline Alkaline phosphatase $(\mathrm{IU} / \mathrm{l})(35-105 \mathrm{IU} / \mathrm{l})$ & 284 & 534 & 360 \\
\hline \multicolumn{4}{|l|}{ Aspartate aminotransaminase (IU/l) } \\
\hline$(<45 \mathrm{IU} / 1)$ & 57 & 56 & 69 \\
\hline Alanine aminotransferase $(\mathrm{IU} / \mathrm{l})(<45 \mathrm{IU} / \mathrm{l})$ & 140 & Not done & Not done \\
\hline Creatinine $(\mu \mathrm{mol} / \mathrm{l}) 60-120 \mu \mathrm{mol} / \mathrm{l})$ & 404 & 133 & 1021 \\
\hline Urea $(\mathrm{mmol} / \mathrm{l}) 3-8 \mathrm{mmol} / \mathrm{l})$ & 41 & $10 \cdot 7$ & 54 \\
\hline \multicolumn{4}{|c|}{ Follow up findings } \\
\hline Creatinine $(\mu \mathrm{mol} / \mathrm{l})$ & 125 & 97 & 140 \\
\hline Bilirubin $(\mu \mathrm{mol} / \mathrm{l})$ & 8 & 10 & 8 \\
\hline Alkaline phosphatase (IU/l) & 76 & 174 & 122 \\
\hline Liver biopsy & Severe & Mixed & Severe \\
\hline & cholestasis & cholangiolitic & cholestasis \\
\hline & & $\begin{array}{l}\text { and hepatitic } \\
\text { changes }\end{array}$ & $:$ \\
\hline
\end{tabular}

^Values in parentheses are normal ranges.

\section{Comment}

These three patients developed a severe debilitating illness from which they took several months to recover. As stanozolol is a $C_{17}$ substituted testosterone it is reasonable to expect cholestatic jaundice to be a complication. Cicardi et al performed liver biopsies in 11 patients receiving long term treatment with stanozolol or danazol, or both: one patient with normal serum bilirubin concentration and alkaline phosphatase activity showed cholestasis. $^{2}$ The mixed cholangiolitic and hepatitic changes seen on histological examination in case 2 differed from those seen in our two other cases but were similar to those described in the one previously recorded case, in which a hypersensitivity reaction was thought to be the underlying process. $^{1}$

The paucity of reports of jaundice associated with stanozolol treatment may be related to the infrequent use of this drug in the past. Prescription of stanozolol has increased recently because of its reported efficacy in the treatment of postphlebitic syndromes. ${ }^{3}$ We suspect that many cases may have gone unrecognised owing to the comparatively long period between the start of treatment and the development of symptoms (one to five months). Although this is unusual for most drug reactions, such prolonged latent periods are not uncommon with anabolic steroids. ${ }^{4}$

Renal impairment is a well recognised complication of severe cholestasis, and experimental work has emphasised the role of prerenal factors. ${ }^{5}$ One patient (case 3) was maintained on diuretics; these were started six months before he developed renal failure and may have increased the tendency of cholestasis to lead to renal failure. Two patients (cases 1 and 3) continued to have renal impairment several months later; this raises the possibility that they had pre-existing renal disease that contributed to the development of hepatic damage.

One of our patients (case 1) was reported on at a meeting of the British Association for the Study of the Liver, which has a section devoted to adverse drug reactions affecting the liver, and as a result the two other cases came to light. This encouraged us to coordinate this report of three recent, similar adverse reactions to stanozolol seen in different parts of the country. We suggest that other specialist societies might consider a similar scheme. 1 Slater SD, Davidson JF, Patrick RS. Jaundice induced by stanozolol hypersensitivity. Postgrad
Med I 1976;52:229-32.

2 Cicardi M, Bergamaschini L, Tucci A, et al. Morphological evaluation of the liver in hereditary angioedema patients on long term treatment with androgen derivatives. $\mathcal{F}$ Allergv Clin Immunol $1983 ; 72: 294-8$.
3 Burnand K, Clemenson G, Morland M, Jarrett PEM, Browse NL. Venous lipodermatosclerosis: treatment by fibrinolytic enhancement and elastic compression. Br Med $\mathcal{F}$ 1980;280:7-11.

4 Kamal IG. Hepatic lesions caused by anabolic and contraceptive steroids. Semin Liver Dis 1981;1:116-27.

5 Green J, Beyar R, Bomzon L, Finberg JPM, Better OS. Jaundice, the circulation and the kidney. Nephron 1984;37:145-52.

(Accepted 28 November 1986)

Royal Hallamshire Hospital, Sheffield S10 2JF

R S EVELY, MRCP, registrar, department of haematology

D R TRIGER, FRCP, reader in medicine

Selly Oak Hospital, Birmingham B29 6JD

J P MILNES, MRCP, senior registrar

T S LOW-BEER, FRCP, consultant physician

King's College Hospital, London SE5 8RS

ROGER WILLIAMS, FRCP, consultant physician

Correspondence to: Dr Evely.

\section{Guillain-Barré syndrome after myocardial infarction}

Acute polyneuropathy of the Guillain-Barré type is known to occur after infection, immunisation, and surgery. ${ }^{2}$ We describe two cases in which it occurred after myocardial infarction.

\section{Case reports}

CASE 1

A 46 year old white man, who had previously been well, gave a 12 hour history of severe retrosternal pain, sweating, and nausea. He was obese and had smoked 20 cigarettes daily between the ages of 16 and 36 . Acute inferior myocardial infarction was evident on electrocardiography, with ST segment elevation and T wave inversion in leads II, III; and aVF, and biochemically, with raised serum creatine kinase, lactate dehydrogenase, and aspartate aminotransferase activities. Full blood count, erythrocyte sedimentation rate, results of liver function tests, a chest $x$ ray film, and plasma electrolyte, urea, and glucose concentrations were normal. He made an uncomplicated recovery from the infarct and was discharged home after 10 days.

Seventeen days after the initial presentation he was readmitted with upper abdominal pain and leg cramps for which there was no immediately apparent cause. This was followed by progressive profound generalised weakness of the arms and legs with areflexia. A computed tomogram of the brain was normal. Cerebrospinal fluid obtained by lumbar puncture showed a raised protein concentration of $0.96 \mathrm{~g} / \mathrm{l}$ but no pleocytosis. Nerve conduction studies confirmed the presence of a generalised polyneuropathy. Screening for porphyrins and antinuclear factor and viral serology gave negative results. Two months later he had made a full recovery with no treatment other than physiotherapy.

\section{CASÉ 2}

A 65 year old white woman, previously well, gave a five day history of progressively severe chest pain associated with upper back pain, with nausea on the day of admission. She smoked 20 cigarettes daily. Acute anterior myocardial infarction was evident on electrocardiography, with widespread new $T$ wave inversion, and biochemically, with raised serum creatine kinase, lactate dehydrogenase, and aspartate aminotransferase activities. Full blood count, erythrocyte sedimentation rate, results of liver function tests, a chest $x$ ray film, and plasma electrolyte, urea, and glucose concentrations were normal.

Her chest and back pain resolved and she did not suffer any cardiovascular complications of the infarct, but she remained lethargic and complained of distal paraesthesia in the arms and legs after the first week. Sluggishness of deep tendon reflexes was noted 15 days after admission and areflexia with bilateral papilloedema by day 22. Computed tomography of the brain showed only mild cerebral atrophy. Cerebrospinal fluid obtained by lumbar puncture showed a raised protein concentration of $1 \cdot 2 \mathrm{~g} / \mathrm{l}$ but no pleocytosis. Nerve conduction studies confirmed the presence of generalised polyneuropathy. Screening for antinuclear factor and viral serology gave negative results. Three months later there was good return of motor function and the papilloedema had resolved. She received no treatment other than physiotherapy.

\section{Comment}

Both cases showed typical features of the Guillain-Barré syndrome; the papilloedema in case 2 was unusual but has been described previously. ${ }^{3}$ Myocardial infarction as a precipitant of acute polyneuropathy has not been 